\title{
The rule-based insensitivity effect: a systematic review
}

\author{
Ama Kissi ${ }^{\text {Corresp., } 1}$, Colin Harte ${ }^{1}$, Sean Hughes ${ }^{1}$, Jan De Houwer ${ }^{1}$, Geert Crombez ${ }^{1}$ \\ ${ }^{1}$ Department of Experimental-Clinical and Health Psychology, Ghent University, Ghent, Belgium \\ Corresponding Author: Ama Kissi \\ Email address: ama.kissi@ugent.be
}

Background. Adherence to inaccurate rules has been viewed as a characteristic of human rule-following (i.e., the rule-based insensitivity effect; RBIE) and has been thought to be exacerbated in individuals suffering from clinical conditions. This review intended to systematically examine these claims in adult populations.

Methodology. We screened 1464 records which resulted in 21 studies that were deemed eligible for inclusion. Each of these studies was examined to determine: (1) if there is evidence for the RBIE in adults and (2) if this effect is larger in those suffering from psychological problems compared to their nonsuffering counterparts. In addition, we investigated how (3) different operationalizations of the RBIE, and (4) the external validity and risks of bias of the experimental work investigating this effect, might influence the conclusions that can be drawn from the current systematic review.

Results. (1) Out of the 20 studies that were relevant for examining if evidence exists for the RBIE in adults, only 11 were eligible for vote counting. Results showed that after the contingency change, the rule groups were more inclined to demonstrate behavior that was reinforced before the change, compared to their non-instructed counterparts. Critically, however, none of these studies examined if their no-instructions group was an adequate comparison group. As a result, this made it difficult to determine whether the effects that were observed in the rules groups could be attributed to the rules or instructions that were manipulated in those experiments. (2) The single study that was relevant for examining if adults suffering from psychological problems demonstrated larger levels of the RBIE, compared to their non-clinical counterparts, was not eligible for vote counting. As a result, no conclusions could be drawn about the extent to which psychological problems moderated the RBIE in that study. (3) Similar procedures and tasks have been used to examine the RBIE, but their precise parameters differ across studies; and (4) most studies report insufficient information to evaluate all relevant aspects affecting their external validity and risks of bias.

Conclusions. Despite the widespread appeal that the RBIE has enjoyed, this systematic review indicates that, at present, only preliminary evidence exists for the idea that adults demonstrate the RBIE and no evidence is available to assume that psychological problems exacerbate the RBIE in adults.

The systematic review was registered in PROSPERO (CRD42018088210). 


\section{The rule-based insensitivity effect: a systematic review}

2 Ama Kissi $^{1}$, Colin Harte ${ }^{1}$, Sean Hughes ${ }^{1}$, Jan De Houwer ${ }^{1}$, Geert Crombez ${ }^{1}$

3

$4 \quad{ }^{1}$ Department of Experimental-Clinical and Health Psychology, Ghent University, Ghent, East-

5 Flanders, Belgium

6

7 Corresponding Author:

8 Ama Kissi $^{1}$

9 Henri Dunantlaan 2, 9000 Gent, Belgium.

10 Email address: Ama.Kissi@UGent.be 


\section{Abstract}

12 Background. Adherence to inaccurate rules has been viewed as a characteristic of human rule-

13 following (i.e., the rule-based insensitivity effect; RBIE) and has been thought to be exacerbated

14 in individuals suffering from clinical conditions. This review intended to systematically examine 15 these claims in adult populations.

16 Methodology. We screened 1464 records which resulted in 21 studies that were deemed eligible 17 for inclusion. Each of these studies was examined to determine: (1) if there is evidence for the 18 RBIE in adults and (2) if this effect is larger in those suffering from psychological problems 19 compared to their non-suffering counterparts. In addition, we investigated how (3) different 20 operationalizations of the RBIE, and (4) the external validity and risks of bias of the 21 experimental work investigating this effect, might influence the conclusions that can be drawn 22 from the current systematic review.

23 Results. (1) Out of the 20 studies that were relevant for examining if evidence exists for the RBIE in adults, only 11 were eligible for vote counting. Results showed that after the contingency change, the rule groups were more inclined to demonstrate behavior that was reinforced before the change, compared to their non-instructed counterparts. Critically, however, none of these studies examined if their no-instructions group was an adequate comparison group. As a result, this made it difficult to determine whether the effects that were observed in the rules groups could be attributed to the rules or instructions that were manipulated in those experiments. (2) The single study that was relevant for examining if adults suffering from psychological problems demonstrated larger levels of the RBIE, compared to their non-clinical counterparts, was not eligible for vote counting. As a result, no conclusions could be drawn about the extent to which psychological problems moderated the RBIE in that study. (3) Similar procedures and tasks have been used to examine the RBIE, but their precise parameters differ across studies; and (4) most studies report insufficient information to evaluate all relevant aspects affecting their external validity and risks of bias.

37 Conclusions. Despite the widespread appeal that the RBIE has enjoyed, this systematic review indicates that, at present, only preliminary evidence exists for the idea that adults demonstrate the RBIE and no evidence is available to assume that psychological problems exacerbate the RBIE 40 in adults.

41

42 The systematic review was registered in PROSPERO (CRD42018088210). 


\section{Introduction}

44 Rules ${ }^{1}$ constitute a set of statements that can govern behavior in various domains such as personal, professional, social, and legal contexts. In most cases adherence to rules like "eat healthily if you want to live long," "do not offend your boss," "do not gossip about your friends," and "do not drink and drive" is beneficial, in so far as doing so allows the individual to more readily obtain positive consequences (e.g., a long life, job certainty) or avoid negative ones (e.g., losing your friends, getting a fine). Yet despite the consequences of rule-following, rules can also continue to exert control over behavior even when they are no longer accurate. Within the behavioral-analytic literature, this pattern of behavior has been referred to as the "rule-based insensitivity effect" (RBIE) and has been defined as "an insensitivity of behavior to other contingencies ${ }^{2}$ due to rule-following” (see Kissi, Hughes, De Schryver, De Houwer, \& Crombez, 2018, p. 1).

To illustrate this effect more clearly, consider the following example. Imagine

56

57

58

participants are asked to complete a learning task and are assigned to one of two groups: an instructions or no-instructions group. In both groups, they can initially earn points if they press the spacebar rapidly in the presence of a green square. Before starting the task, the instructions group is accurately informed about the contingencies operating in the task (i.e., that pressing the spacebar rapidly will cause them to earn more points). The no-instructions group, however, is not informed about these contingencies and thus has to figure out how to earn points via trialand-error. About half way through the task, the task-contingencies are changed so that participants now have to press the spacebar slowly in order to earn points. Under such circumstances, it would be assumed that there is evidence for the RBIE if participants who were initially provided with accurate instructions, earned fewer points after the task-contingency change compared to those that did not receive such instructions (see Kissi et al., 2018 and LeFrancois et al., 1988 for similar procedures).

Over the past decades, a number of studies have empirically examined the RBIE in the laboratory (e.g., Donadeli \& Strapasson, 2015; Joyce \& Chase, 1990; Miller, Hirst, Kaplan, DiGennaro Reed, \& Reed, 2014; Ninness \& Ninness, 1998). Elsewhere, applied researchers and clinical psychologists have appealed to this effect when attempting to understand and treat psychological suffering. For instance, it has been argued that the RBIE is at the core of various problems such as addiction, depression, and personality disorders (Baruch, Kanter, Busch, Richardson, \& Barnes-Holmes, 2007; Blackledge \& Drake, 2013; Hayes \& Gifford, 1997; McAuliffe, Hughes, \& Barnes-Holmes, 2014; Törneke, Luciano, \& Salas, 2008; Törneke, 2010). The idea here is that psychological problems are - amongst other things - the consequence of

\footnotetext{
${ }^{1}$ Within the behavioral-analytic literature terms such as instructions and rules are often used interchangeably. Yet it is important to note that they are descriptive and not functional-analytical terms, given that they did not emerge from inductive, functional-analytic research. As such, in the current manuscript we will use them interchangeably as a way to orient the reader toward a specific class of verbal stimuli.

2 These contingencies can refer to other contingencies in the environment as well as those specified by a rule.
} 
77 adherence to rules that reduce one's ability to persist or adapt to what is required in a given 78 situation (Blackledge \& Drake, 2013).

Nevertheless, and despite the attention that rules and the RBIE have received, there is

80

81

82

83

84

85

86

87

88

89

90

91

92

93

94

95

96

97

98

99

100

101

102

103

104

105

106

107

108

109

110

111

currently no systematic review available of the experimental work examining this effect. This is unfortunate, given that such a review is essential to draw general conclusions about the RBIE which can inform future research and clinical practice. Towards this end, we systematically reviewed the RBIE literature to examine if: (1) there is sufficient empirical support for this effect in adults, and (2) adults suffering from psychological problems display larger levels of this effect compared to those that do not suffer from these problems. We also investigated how (3) different operationalizations of the RBIE, and (4) the external validity and risks of bias of the experimental work investigating this effect, might influence the conclusions that can be drawn from the current systematic review.

\section{Survey methodology}

\section{Protocol and Registration}

The review protocol was designed in line with the PRISMA guidelines (Moher, Liberati, Tetzlaff, \& Altman, 2009) and registered in PROSPERO (CRD42018088210).

\section{Information Sources and Search Strategy}

To identify as many relevant records as possible, multiple electronic databases were searched (i.e., "Web of Science", "PsychINFO", "PsychArticles", and "PubMed [Medline]") using the search terms: "rule governed behavior", "rule-governed behavior", "rule governed behaviour", "rule-governed behaviour”, "verbal regulation”, "instructional control”, "verbal rule”, "instructed behavior”, "instructed behaviour”, "instructed learning”, "instruction following”, "instruction-following”, "rule following”, and "rule-following." These search terms were iteratively developed with experts on systematic reviews and rule-governed behavior, and were subsequently presented to other experts on systematic reviews and rule-governed behavior who were not associated with the project. All searches were conducted on 4/10/2017 by the first author (i.e., Ama Kissi) and yielded 1459 records. Five novel records were additionally retrieved by contacting experts in the field, which resulted in a final set of 1464 records that were assessed for eligibility.

\section{Eligibility Criteria}

There were several general criteria that a record had to meet before being included in the current review: (1) it had to be a peer-reviewed journal article, (2) it had to be written in English, (3) it had to include a study that examined the RBIE by first asking participants to follow socially -or self-generated rules that initially corresponded with a set of contingencies but then became inaccurate after a contingency change, and (4) this study had to have an overall sample

Peer] reviewing PDF | (2020:01:45226:1:1:NEW 28 May 2020) 
112 age of at least 18 years, (5) and at least 10 participants within each experimental group (see Van

113 Ryckeghem, Van Damme, Eccleston, \& Crombez, 2018 for similar eligibility criteria).

114 Furthermore, depending on the research objective under scrutiny, the individual studies

115 reported in these records had to meet an additional number of criteria to be deemed eligible for

116 inclusion. For instance, when addressing our first research question ("Is there evidence for the

117 rule-based insensitivity effect in adults?"), we only included studies that did not focus upon

118 individuals with clinical problems. That is, only studies which used convenience samples (e.g.,

119 students), samples taken from the general population, or those that were not diagnosed with

120 clinical problems, or reported sub-clinical problems were included. Studies were deemed eligible

121 for answering our second research question ("Do adults suffering from psychological problems

122 display a larger RBIE compared to their non-clinical counterparts?"), if they used the following

123 samples: individuals diagnosed with psychological problems (clinical group) or those who

124 scored high on instruments measuring psychological problems but were not formally diagnosed

125 with a clinical problem (sub-clinical group), and a comparison group consisting of individuals

126 that did not suffer from the above problems or were recruited via convenience sampling.

\section{Study Selection Process}

128

129

130

131

132

133

134

135

136

137

138

139

140

141

142

143

144

145

146

147

148

Out of the 1464 records that were assessed for eligibility, 1446 were excluded because they were not published in English $(n=123)$, were not peer-reviewed journal articles $(n=207)$ (e.g., book chapters, dissertations, or conference papers) or dealt with a topic that did not meet our inclusion criteria $(n=1044)$. Three journal articles were, furthermore, omitted because they did not provide sufficient information to assess their eligibility. An additional 69 journal articles were excluded that were on the RBIE but were non-experimental $(n=6)$, relied on non-adult samples $(n=14)$, used samples with less than 10 participants per experimental condition $(n=$ $41)$, or did not include a contingency change or manipulate accurate rules $(n=8)$. This resulted in a remaining total of 18 records consisting of 22 individual studies. One of these studies was subsequently omitted because it did not have at least 10 participants within each experimental group. As such, 21 studies were finally included in the systematic review. The eligibility of all studies were independently assessed by the first two reviewers (i.e., Ama Kissi and Colin Harte) initial agreement $=99 \%[\mathrm{kappa}=.98]$, agreement after discussion $=100 \%[\mathrm{kappa}=1.00])$. See Fig. 1 for the flow diagram of the study selection process.

\section{INSERT FIGURE 1 HERE-}

\section{Qualitative Synthesis: Coding Procedure and Items}

Certain characteristics of each of the 21 studies were independently coded by the first two reviewers (i.e., Ama Kissi and Colin Harte) (initial inter-reviewer agreement $=96 \%$, interreviewer agreement after discussion $=100 \%$ ). These characteristics involved the source, study, task, and sample characteristics. The source characteristics entailed the year in which the first author published the study and the country where s/he worked in when the paper was published.

Peer] reviewing PDF | (2020:01:45226:1:1:NEW 28 May 2020) 
149 The study characteristics referred to the type of task, experimental design, procedure, and

150

151

152

153

154

155

156

157

158

159

160

161

162

163

164

165

166

167

168

169

170

171

172

173

174

175

176

177

178

179

180

181

182

183

184

185

186

187 analytic method that were used to examine the RBIE. Furthermore, the task characteristics entailed whether a study reported the exact instructions or rules that were used, how these instructions or rules were delivered (orally versus written) or generated (self [i.e., by the rulefollower]-versus socially [i.e., by another person than the rule-follower]), the reinforcement schedules that were used, the required behavioral responses, the type of consequential stimuli that were used, whether the contingency change was (un)signaled, whether a description was provided of who the experimenter was, and whether the experimenter was present. Finally, the sample characteristics that were evaluated were the size and mean age of the sample, the ratio of males:females, and whether the sample was selected (i.e., from either a healthy, clinical or subclinical population, or the general population) or non-selected (i.e., a convenience sample). These characteristics were evaluated for each experimental group.

\section{Quantitative Synthesis: Vote Counting}

To synthesize the quantitative results of the included studies, we used the vote-counting method. This method was chosen because not all studies reported effect sizes or information that could be used to calculate such estimates. According to the Cochrane Collaboration guidelines for systematic reviews, the best way to use the vote-counting method is by assessing whether the results of the empirical studies fall into one of two categories: "positive" or "negative" effects (see Deeks, Higgins \& Altman, 2008). Positive effects refer to results that are in favor of the predicted relationship between the independent and dependent variable(s), whereas negative effects refer to outcomes that are in the opposite direction of what is expected. We only judged (or voted) whether a study had positive or negative effects if it included a comparison group (i.e., a no-instructions group). That is, a group that received the same treatment as the rules group but was not asked to follow the instructions or rules that these groups had to follow. We applied this restriction because we argued that such a comparison group is necessary if a study wishes to draw conclusions about the extent to which certain rules or instructions are responsible for the observed effects. In doing so, performances in the comparison group would serve as a baseline of how people behave in the absence of these types of rules or instructions. As such, if a study did not include such a comparison group, we argued that its effects were unclear (i.e., there was insufficient information to cast votes).

The outcome data that were preferably used to cast votes were measures of the central tendency (e.g., mean, mode, or median) of participants' responses, during all blocks after the contingency change. If a study, however, did not report participants' performances during all blocks following the contingency change, but only during a fraction of the trials after this change, we limited our analysis to that data. In the unfortunate event that no data was provided that could be used to draw conclusions about the central tendency of participants' responding after the contingency change, we relied on the conclusions that the authors formulated themselves (Cerutti, 1991; Torgrud, Holborn, \& Zak, 2006 [Experiments 1 and 2]). Finally, in all of the above cases, if there were multiple contingency changes we only considered participants' 
188

189

190

191

192

193

194

195

196

197

198

199

200

201

202

203

204

205

206

207

208

209

210

211

212

213

214

215

216

217

218

219

220

221

222

223

224

225

responding after the first change. This was, specifically, done to prevent carry-over effects from influencing the interpretation of the results.

All votes were independently cast by the first two reviewers (i.e., Ama Kissi and Colin Harte) in the following manner (inter-reviewer agreement $=100 \%$, kappa $=1.00$ ). For the first research question ("Is there evidence for the rule-based insensitivity effect in adults"), study results were considered positive if evidence was found for the RBIE. That is, if participants did not adapt to a novel task-contingency or rule (i.e., if their behavior was still in line with the selfgenerated or socially-provided rule that was in place before the contingency change).

Furthermore, study results were considered negative if one of three conditions were met. First, if a task-contingency was changed and participants' behavior was now always in line with this novel contingency. Second, if a self-generated or socially-provided rule was altered, and participants' behavior was now always in accordance with this novel rule. Third, if both a taskcontingency and rule was changed, and participants' behavior was now always in line with this novel contingency and rule.

To cast votes for the second research question ("Do adults suffering from psychological problems display a larger RBIE compared to their non-clinical counterparts?"), we first assessed whether there was evidence supporting the RBIE. This was achieved in the same way as outlined above. If evidence for the effect was found, we subsequently examined if it was larger (in absolute terms) in the (sub-)clinical groups, compared to their non-clinical counterparts. If this was the case, then the study results would be categorized as positive. If these results were in the opposite direction, we would categorize them as negative.

Assessment of Risks of Bias

We, additionally, scrutinized the internal validity of the included studies. This examination involved assessing risks of bias using the Cochrane Collaboration tool for assessing risks of bias (Higgins \& Altman, 2008) and the Office of Health Assessment and Translation (OHAT) Risk of Bias Rating Tool (NTP, 2015). Risks of bias can be defined as those aspects of a study design that can distort the conclusions that can be drawn from it. For the present review, we evaluated five potential risks of bias: selection, exclusion, performance, detection, and reporting bias. Note that these biases do not cover all risks of bias that are described in the Cochrane Collaboration and OHAT risks of bias tools. Indeed, given that these tools were not originally developed for assessing risks of bias in experimental-behavioral research, we selected and reformulated those risks of bias that we deemed relevant for evaluating such work.

For each of the studies, judgments of risks of bias (coded in terms of 'high', 'low', or 'unclear' risk of bias) were made in the following ways. To examine the possibility that there were systematic differences between the baseline characteristics of the groups that were compared (i.e., a selection bias), we examined: 1) the adequateness of a study's sequence generation procedure, 2) whether the experimental group to which participants were allocated to was concealed, 3) participants' past experiences with the experiment, and 4) the possibility that 
226

227

228

229

230

231

232

233

234

235

236

237

238

239

240

241

242

243

244

245

246

\section{Results}

they were misclassified to experimental groups. Furthermore, to assess the likelihood of an exclusion bias (i.e., systematic differences in the exclusion of participants from a study) we evaluated the possibility that there were systematic differences between groups with regard to the amount, nature, and handling of missing outcome data. To determine the risk of a detection bias (i.e., systematic differences between groups in how outcomes are determined) we evaluated: 1) the validity and reliability of the outcome assessment methods, 2) the adequateness of the outcome assessments, 3 ) the adequateness of the methods that were used to determine sample sizes and 4) the adequateness of the methods used to analyze the results. Judgments concerning performance biases (i.e., systematic differences between groups in how they were treated or exposed to factors other than the manipulation of interest) were made by examining whether: 1) the experimental contexts were standardized, 2) participants were informed about the study objectives, and 3) researchers and/or participants were informed about the experimental group to which participants were allocated to. Finally, to assess the possibility of a reporting bias (i.e., systematic differences between reported and unreported findings) we assessed potential discrepancies between the outcomes that were specified prior to the study and those that were eventually reported.

\section{Assessment of External Validity}

To determine the external validity of each of the included studies, we examined whether a study adequately described its eligibility criteria (in terms of age, sex, and diagnosis), the demographics of its sample, its study setting, its recruitment procedure, and the experimental manipulations that it used per experimental group.

\section{Summaries of Included Studies}

For more information about the included studies, see Appendix S1 which contains summaries of all the included studies. These summaries are structured according to those studies that were deemed eligible to address the first $(k=20)$ and second research question $(k=1)$.

There are two points worth noting about these summaries. First, they only include descriptions of those results that were relevant for the current research questions. As such, these summaries may contain less information than provided in the original study reports. Second, whenever it is mentioned that there is a difference between groups, this denotes an absolute and not a statistically significant difference.

\section{Qualitative Synthesis: Source, Study, Task and Sample Characteristics}

Source characteristics. The majority of the studies were written by a first author who did not work in the USA at the time of publication (i.e., Belgium $[k=3]$, Canada $[k=4]$, France $[k=2]$, Norway $[k=2]$, Switzerland $[k=1]$, USA $[k=9])$ and most studies were published in the $2000 \mathrm{~s}(k=12)$. 
262

263

264

265

266

267

268

269

270

271

272

273

274

275

276

277

278

279

280

281

282

283

284

285

286

287

288

289

290

291

292

293

Study characteristics. In the majority of the included studies, participants completed a conditional discrimination task $(k=14)$. In all of the studies, participants were allocated to one of the experimental groups, and conclusions about the RBIE were drawn by comparing the performances between these groups after a contingency change. Most of these studies examined the RBIE by examining how rules affected adaptation to changes $(k=11)$ or reversals $(k=6)$ in the non-instructed task-contingencies. See Table 1 for an overview of the study characteristics for each included study. -INSERT TABLE 1 HERE-

Task characteristics. In each of the 21 included studies, a description was provided of the precise instructions or rules that were used. Seventeen of these studies reported how they manipulated their rules or instructions. In 16 of these cases, this was via written text (five of these studies also provided additional oral rules or instructions). The majority of the studies used socially-generated rules ( $k=19$; five of these studies also used self-generated rules), intermittent reinforcement schedules $(k=15$; two of these studies also combined such schedules with continuous reinforcement schedules) and tasks that required simple discrete responses $(k=14$; in two of these studies discrete choice responses were also required). In 18 out of the 21 studies, points were used as consequential stimuli which were often exchangeable for a monetary reward ( $k=10$ out of 18). Of those studies that reported whether a contingency change was announced $(k=9)$, seven of them stated that this was not the case (i.e., it was unannounced). Only one of the studies provided a description of the experimenter. Seven studies provided information about the presence of the experimenter. Of those studies, five stated that s/he was not present during the experiment. See Tables 2 and 3 for an overview of the task characteristics for each included study.

INSERT TABLE 2 HERE-

INSERT TABLE 3 HERE-

Sample characteristics. On average, 58 participants were included in the analyses $(S D=$ 33 and range: $21-150)$. The mean age of participants was $20(S D=.16)$ and the average number of females was $34(S D=25)$. Note, however, that these values were based on the two and six studies that reported the mean age and gender proportions of the samples that were included for analyses, respectively. Twenty out of the 21 studies used convenience samples, whereas only one study used students that were selected based on the presence or absence of sub-depressive symptomatology (i.e., Baruch et al., 2007)3.

\footnotetext{
${ }^{3}$ Note that we did not use the schizophrenic patients group from the Monestès et al. (2014) study to address our second research question because it had fewer than ten participants within each experimental group.
} 
294

295

296

297

298

299

300

301

302

303

304

305

306

307

308

309

310

311

312

313

314

315

316

317

318

319

320

321

322

323

324

325

326

327

328

329

330

\section{Quantitative Synthesis: Vote Counting}

To address Research Question 1 ("Is there evidence for the rule-based insensitivity effect in adults?") votes were only cast for the 11 out of the 20 studies that included a no-instructions group as a comparison group. These votes indicated that the results of each of these 11 studies were positive. No judgments could, however, be made for the one study that was relevant for addressing Research Question 2 ("Do adults suffering from psychological problems demonstrate larger levels of the RBIE compared to their non-clinical counterparts?"), because this study did not include a no-instructions group. For an overview of the vote-counting results for both research questions see Table 4.

\section{Assessments of Risks of Bias}

Most of the included studies did not report the necessary information to assess all relevant domains of risks of selection, performance, exclusion, and detection bias. Nevertheless, the following can be said about those study aspects that we could draw conclusions about. Of the eleven out of the 21 studies that used a no-instructions group as a comparison group, none assessed the possibility that this group followed similar rules as the rules groups during the experiment. As a result, it could be that in these studies participants were misclassified to experimental groups. That is, there remains a possibility that participants were inaccurately thought to belong to a comparison group while in fact their behavior was actually governed by rules similar to those manipulated in the experimental groups. Furthermore, for the remaining domains, we argued that there were low risks of bias. Indeed, we argued that there was a low risk of reporting bias, seeing as there was a correspondence between the outcomes that were specified prior to the study and those that were actually reported. With respect to standardization of the experimental contexts, we argued that there was a low probability that the experimental groups were treated differently (performance bias). We also argued that there was a low probability that the methods that were used to assess the study outcomes were invalid or unreliable, and that the experimental groups differed with respect to how these outcomes were assessed (detection bias). See Appendices S2 and S3 for an overview of the judgments that were made for each aspect or domain of a study that could lead to a risk of bias.

\section{Assessment of External Validity}

The majority of those included studies that were relevant for examining our first research question ("Is there evidence for the rule-based insensitivity effect in adults?") ( $k=20)$ did not report all relevant demographics (i.e., mean age, sex, and education level) of their samples $(k=$ 13) nor their recruitment procedure $(k=13)$. Most of these studies $(k=16)$, however, explicitly described the setting in which the experiment took place, and all of them provided a detailed description of the experimental manipulations per group. The one study that was relevant for examining our second research question ("Do adults suffering from psychological problems 
display a larger RBIE compared to their non-clinical counterparts?"), selected participants based on the presence or absence of sub-clinical symptoms of depression, reported the eligibility criteria that they used, the demographics of their sample, and the experimental manipulations per group. Nevertheless, this study did not provide information about the experimental setting nor the procedure used to recruit participants.

\section{Discussion}

Rule-following is an essential human ability which can allow people to contact certain consequences more quickly and efficiently. Yet it has been argued that, under some conditions, this ability can also undermine people's sensitivity to other environmental contingencies (i.e., RBIE) and can lead to a wide range of clinical problems. Despite the presumed importance of this effect for our understanding of human behavior in general and human suffering in particular, to date, no systematic review has been carried out of the experimental work that has examined these claims. To this end, the present study systematically reviewed the RBIE literature to determine: 1) if there is evidence for the RBIE in adults and 2) if this effect is larger in adults suffering from psychological problems compared to their non-suffering counterparts. In addition, we investigated how 3 ) different operationalizations of the RBIE, and 4) the external validity and risks of bias of the experimental work investigating this effect, might influence the conclusions that can be drawn from the current systematic review.

Our results can be summarized as follows: (1) there is preliminary evidence for the idea that adults demonstrate the RBIE; (2) at present, there is no evidence to support the claim that psychological problems moderate the RBIE in adults; (3) similar procedures and tasks have been used to examine the RBIE, however, their precise parameters differed across studies; and (4) most studies did not report sufficient information to evaluate all relevant aspects concerning their external validity and risks of bias. In the following sections, we will elaborate on each of the above-described points and their implications for our understanding of this effect.

\section{Evidence for the RBIE}

Remarkably, only 11 out of the 20 studies that were deemed relevant for addressing our first research question ("Is there evidence for the rule-based insensitivity effect in adults?") were eligible for vote-counting, because they included a no-instructions group (as a comparison group). Of these studies, the results showed that after the contingency change, the rule groups were more inclined to demonstrate behavior that was reinforced before the change, compared to their non-instructed counterparts. At first glance, this seems to suggest that when adults are asked to follow initially accurate rules, they experience more difficulties adapting to changes in contingencies (compared to when they are not asked to follow such rules). Nevertheless, the risk of bias assessments showed that such a conclusion may be premature because none of the 11 included studies assessed whether their no-instructions groups functioned as adequate comparison groups. That is, none of these studies examined if, during the experiment, 
368

369

370

371

372

373

374

375

376

377

378

379

380

381

382

383

384

385

386

387

388

389

390

391

392

393

394

395

396

397

398

399

400

401

402

403

404

405

participants in their comparison group did not follow rules about the task-contingencies that were similar to those followed by the rule groups. As a result, this made it difficult to determine whether the effects that were observed in the rules groups could be attributed to the rules or instructions that were manipulated in those experiments.

Despite the fact that we found preliminary evidence for the RBIE in all 11 studies, it is important to acknowledge that there might be variables that increase or decrease the likelihood of observing this effect. For instance, according to past work, the RBIE might be less likely to occur if the experimenter is not physically present (e.g., Kroger-Costa \& Abreu-Rodrigues, 2012), participants are provided with inaccurate as opposed to accurate instructions before a contingency change occurs (e.g., Hojo, 2002), and if the consequences for behaving in line with the actual task-contingencies outweigh those of following the rule (Donadeli \& Strapasson, 2015). Unfortunately, a systematic examination of potential moderators of the RBIE (besides the moderating impact of the absence/presence of psychological problems) was beyond the scope of this systematic review. Nonetheless, we deem such an examination vital as it might further our understanding of the robustness of this effect. As such, we recommend that future work systematically examines those variables that might decrease or increase the RBIE.

\section{Psychological Problems and the RBIE}

Despite the key role that the RBIE has been argued to play in psychological problems, only one of the included studies was deemed relevant for examining this idea. However, given that this study did not include a no-instructions group, no judgments could be made about the extent to which evidence was found for the RBIE, and whether psychological problems moderated this effect. This suggests that there is currently no evidence available to draw firm conclusions about the relationship between psychological problems and the RBIE in adults. Furthermore, even if we evaluated the peer-reviewed journal articles $(n=69)$ which examined the RBIE but were omitted because they: (a) used samples smaller than 10, (b) samples from non-adult populations, (c) used non-experimental designs, and/or (d) did not manipulate rules or include a contingency change, we still failed to identify many relevant studies. Indeed, such a revised search only resulted in an additional four studies: two studies that investigated the impact of sub-clinical depressive symptoms in adolescents (McAuliffe et al., 2014 [Experiments 1 and 2]), one study that examined that of ADHD in children (Kollins, Lane, \& Shapiro, 1997) and another study that examined that of schizophrenia in samples smaller than 10 (Monestès et al., 2014). We, therefore, strongly recommend that more work is conducted on the relationship between the RBIE and psychological problems to better inform clinical theory and treatment.

When carrying out such work, researchers should also explore certain variables that could moderate this effect in clinical groups. For instance, it might be that clinical groups (e.g., arachnophobic) are more insensitive to contingency changes if they follow pathology-relevant (e.g., "If you want to remain alive, always avoid places where there could be spiders") but not pathology-irrelevant rules (e.g., "to gain points press the blue button"). Likewise, it is possible 
406 that different clinical groups (people suffering from psychosis vs. depression) demonstrate

407 different levels of the RBIE because of differences in the origins (generated by imaginary agents 408 vs. self-generated) of the rules they follow. Another possibility is that variations in the elements 409 of the rules (i.e., the described stimuli [all spiders vs. tarantulas], responses [avoiding spiders vs. 410 attacking them], and contexts [all spider habitats vs. the basement]), might contribute to 411 differences in how people suffering from similar conditions (e.g., arachnophobia) adapt to 412 contingency changes. We believe that such an endeavor would be useful because it could aid 413 clinicians in developing more targeted treatments.

\section{Operationalization of the RBIE}

415

416

417

418

419

420

421

422

423

424

425

426

427

428

429

430

431

432

433

434

435

436

437

438

439

440

441

442

443

Our coding of task and study characteristics revealed that although most of the included studies used similar tasks and procedures, the precise parameters that were involved often differed. Specifically, many studies used conditional discrimination tasks during which participants could initially gain points if they followed the rules they received from the experimenter. In most of these studies, the task-contingencies were subsequently altered after a number of trials so that the previously effective rules were rendered ineffective. To illustrate, consider Kissi et al.'s (2018) Matching-To-Sample (MTS) task. This task consisted of two experimental phases. On every trial, participants were presented with four images. One image called the 'sample stimulus' - was presented at the top of the screen and always consisted of three identical symbols or letters (e.g., TTT). Three other images - called the comparison stimuli - were presented at the bottom of the screen. One of these images had two symbols or letters that were identical to the sample stimulus (e.g., TT\%; most-like comparison stimulus), another had one symbol or letter identical to the sample stimulus (e.g., $\mathrm{T} \% \%$; moderate-like comparison stimulus), while the third had no symbols or letters in common with the sample stimulus (e.g., $\% \% \%$; least-like comparison stimulus). During the first phase of the experiment, participants could obtain points if they selected the comparison stimulus that was most-like the sample stimulus. However, during the second phase of the experiment, the task-contingencies were changed. Now, participants gained points whenever they selected the comparison stimulus that was least-like the sample stimulus. To examine the RBIE, some participants were given instructions telling them how to gain points in the task, whereas others had to learn about the task-contingencies via trial-and-error. This task is a conditional discrimination task because reinforcement for responses was conditional upon the characteristics of the sample stimulus.

Critically, despite the fact that most included studies used similar tasks, the precise stimuli (tones vs. images) that were used, the point in time in which the contingency change occurred (e.g., after two vs. three blocks), and the study outcomes (e.g., latencies vs. rate or accuracy of responding) often differed between studies. Generally speaking, if reliable evidence is found for a phenomenon, such variations are often viewed as a potential advantage because they enhance the generalizability of a study's findings. Yet given that, in our opinion, it is unclear whether the RBIE was adequately assessed in any of the included studies in this review, 
444 we believe that this idea cannot be applied to our findings (see the previous sections "Evidence 445 for the RBIE" and "Psychological Problems and the RBIE").

\section{External Validity and Risks of Bias}

447

448

449

450

451

452

453

454

455

456

457

458

459

460

461

462

463

464

465

466

467

468

469

470

471

472

473

474

475

476

477

478

479

480

The results revealed that many studies did not report all relevant demographics of their samples, how they were recruited, if the contingency changes were announced, and if the experimenter was present during the experiment. In addition, no study provided sufficient information to assess all domains of potential risks of bias. Taken together, this suggests that the reports of the included studies did not provide sufficient information to evaluate all coding items assessing their external and internal validity. The lack of such information is particularly problematic in the context of systematic reviews because it limits the conclusions that can be drawn from it. As such, we strongly recommend that, in future work, researchers report all information about their study that may enable readers to more readily draw conclusions about its external and internal validity (see Schulz, Altman, \& Moher, 2010 for guidelines).

\section{Other Considerations}

In many of the studies, there was the implicit assumption that when people were asked to follow accurate rules, their behavior would be exclusively governed by those rules, and that if this was not the case, their actions would be exclusively guided by the task-contingencies. We would argue that such a reasoning might be problematic for two reasons (for similar arguments see Hayes, Brownstein, Haas, \& Greenway, 1986). First, previous work suggests that when humans are not provided with rules they rarely demonstrate purely contingency-shaped behavior. Instead, they often generate and use their own rules about how they should behave in a particular context, based on their (trial-and-error) experiences in that context (Rosenfarb, Newland, Brannon \& Howey, 1992; Shimoff, Matthews \& Catania, 1986). Second, such an interplay between environmental contingencies and rules may have also impacted the behavior of the rule groups that were described in the reviewed studies. Indeed, a closer look at the results of these studies showed that when behavior was considered rule-governed, it was rarely ever the case that participants consistently stuck to the rules they were told to follow. Rather, the results suggest that participants sometimes engaged with the task in ways that were not specified by these rules. There could be two possible explanations for this finding. A first possibility is that these deviations from the rules were unintentional and as such reflected erroneous responding. A second possibility is that instances in which participants discarded the rules that they were told to follow, actually constituted intentional attempts to explore instead of exploit the taskcontingencies (Berger-Tal, Nathan, Meron, \& Saltz, 2014).

If the latter possibility is valid as well as the possibility that rules governed the behavior of the no-instructions groups, then this might suggest that comparisons between instructed and non-instructed groups might not inform us about the effects of rule-governed vs. contingencyshaped behavior per se. Indeed, such comparisons might then rather inform us about the relative 
481 degree to which socially-provided rules vs. environmental contingencies and self-generated rules

482 vs. environmental contingencies influenced the behavior of the instructed and non-instructed

483 groups, respectively. Yet given that we could not assess the plausibility of this assertion in the

484 current study, this idea remains speculative. We, therefore, recommend that future work

485 examines its validity so that we can gain a better understanding of how the RBIE should be

486 conceptualized (e.g., as an insensitivity of behavior to other contingencies due to a stronger

487 reliance on socially-generated rules than environmental contingencies).

488 Finally, to the best of our knowledge, there is currently no consensus about how

489 contingency insensitive and sensitive behavior should be measured. Indeed, if anything, the

490 implicit assumption is that behavior is contingency insensitive if it is not in line with a

491 contingency, whereas it is contingency sensitive if it corresponds with a contingency. We believe

492 that although such operational definitions can be useful in some respects, they lack the precision

493 that is needed to measure these behaviors in a uniform and unambiguous manner. Indeed, given

494 the broad and descriptive nature of these definitions, much variation can exist between studies in

495 how they measure contingency sensitive and insensitive behavior. We believe that, although this

496 is not an issue per se, it can become problematic when one wants to draw general conclusions

497 across studies. We, therefore, recommend that future work offers more precise operational

498 definitions of contingency sensitive and insensitive behavior.

499 Limitations

$500 \quad$ Several factors should be taken into account when interpreting our results. First, to 501 determine whether or not behavior was in line with a previously effective rule and/or a novel 502 contingency we used a liberal criterion. That is, we considered participants' behavior to be in 503 line: 1) with a previously effective rule if they demonstrated behavior that corresponded with this 504 rule on at least a few trials, and 2) with a novel contingency and/or rule if they always behaved in 505 line with this contingency and/or rule. As a consequence, it possible that if a different criterion 506 were used, other findings would have emerged. Second, we opted for vote-counting for our 507 quantitative research synthesis, which unlike the standard meta-analytic approach does not 508 provide information about the magnitude of the observed effects (Koricheva \& Gurevitch, 2013). 509 Nevertheless, to gain some insight into these effects, we conducted a random effects model meta510 analysis using those studies that reported sufficient statistical information. This analysis was 511 based on six studies including a total of 377 participants (i.e., Haas \& Hayes, 2006; Harte et al., 5122017 [Experiment 2], Kissi et al., 2018; Kudadjie-Gyamfi \& Rachlin, 2002; Monestès et al., 513 2017; Monestès et al., 2014). It revealed a significant effect size of .76 (Cohen's $d$ for 514 independent samples; 95\% CI [.41 - 1.12]; $p<.001$ ) indicating that participants had far more 515 difficulties adapting to a contingency change if, prior to the change, they received a rule as 516 opposed to no rule. Third, across all studies that were deemed eligible for vote-counting, 517 preliminary evidence was found for the RBIE. This was surprising, given that, in general, the 518 likelihood of observing the same effect across all studies in a systematic review is rather low 519 (Thornton \& Lee, 2000). Usually, when such an overrepresentation of positive effects is 
520 observed, it is assumed that this might be due to publication bias, i.e., journals' preference for 521 publishing positive over negative findings (Joober, Schmitz, Annable \& Boksa, 2012; Thornton $522 \&$ Lee, 2000). Publication bias is particularly problematic in the context of systematic reviews, 523 because it can lead to an overestimation of the existence of a particular effect. Therefore, we 524 recommend the reader to take this bias into account when interpreting the findings of our 525 systematic review. Finally, we adopted pre-defined inclusion and exclusion criteria which 526 inevitably limited the scope of the review and as such the potential conclusions that can be drawn 527 from it. For instance, we only considered peer-reviewed journal articles that examined one 528 instance of the RBIE and one potential moderator of this effect in adult populations. Similarly, 529 we only included experiments with groups that contained at least 10 participants, which led us to 530 discard naturalistic studies and studies that adopted a single-subject methodology.

\section{Conclusions}

532 For several decades now, the RBIE has been argued to play an important role in human 533 behavior in general and psychological suffering in particular. Yet despite its widespread appeal, 534 the results of this systematic review suggest that strong claims about its existence and role in 535 psychological suffering are currently unsupported and thus far unwarranted. Indeed, at present, 536 only preliminary evidence exists concerning the RBIE in adults and no strong evidence is 537 available to draw conclusions about its role in the development and maintaince of psychological 538 suffering in adults. We, therefore, recommend that more systematic research is conducted on the 539 RBIE so that future work can better evaluate the relevance of this effect for our understanding of 540 human behavior and psychological suffering. 
541 References

542 Baruch, D. E., Kanter, J. W., Busch, A. M., Richardson, J. V, \& Barnes-holmes, D. (2007). The

543

544

545

546

547

548

549

550

551

552

553

554

555

556

557

558

559

560

561

562

563

564

565

566

567

568

569

570

571

572

573

574

575

576

577

578

579

580 differential effect of instructions on dysphoric and nondysphoric persons. The Psychological Record, 57(4), 543-554.

Blackledge, J. T., \& Drake, C. E. (2013). Acceptance and commitment therapy: Empirical and theoretical considerations. In S. Dymond \& B. Roche (Eds.), Advances in relational frame theory and contextual behavioral science: Research and application (pp. 219-252). Oakland, CA: New Harbinger.

Berger-Tal, O., Nathan, J., Meron, E., Saltz, D. (2014). The Exploration-Exploitation Dilemma: A Multidisciplinary Framework. PLOS ONE, 9(4), e95693. Doi: 10.1371/journal.pone.0095693

Bushman, B. J., \& Wang, M. C. (2009). Vote-Counting Procedures in Meta-Analysis. In H. Cooper, L. V. Hedges, \& J. F. Valentine (Eds.), The Handbook of Research Synthesis and Meta-Analysis (2nd ed., pp. 207-220). New York: Russel Sage Foundation.

Cerutti, D. (1994). Compliance with instructions: Effects of randomness in scheduling and monitoring. The Psychological Record, 44, 1-6.

Cerutti, D. T. (1991). Discriminative versus reinforcing properties of schedules as determinants of schedule insensitivity in humans. The Psychological Record, 41, 51-67.

Deeks, J. J., Higgins, J. P. T., Altman, D. G. (Eds.) (2008). Chapter 9: Analysing data and undertaking meta-analyses. In: Higgins J. P. T. \& Green S. (Eds.). Cochrane Handbook for Systematic Reviews of Interventions (Version 5.0, pp. 243-296).Chichester, UK: John Wiley \& Sons.

Dixon, M. R., Hayes, L. J., \& Aban, I. B. (2000). Examining the roles of rule following, reinforcement, and preexperimental histories on risk-taking behavior. Psychological Record, 50(4), 687-704. Doi:10.1007/BF03395378

Donadeli, J. M., \& Strapasson, B. A. (2015). Effects of Monitoring and Social Reprimands on Instruction-Following in Undergraduate Students. Psychological Record, 65(1), 177-188. Doi:10.1007/s40732-014-0099-7

Faber, J., \& Fonseca, L. M. (2014). How sample size influences research outcomes. Dental Press Journal of Orthodontics, 19(4), 27-29. Doi:10.1590/2176-9451.19.4.027-029.ebo

Haas, J. R., \& Hayes, S. C. (2006). When Knowing You Are Doing Well Hinders Performance : Exploring the Interaction Between Rules and Feedback. Journal of Organizational Behavior Management, 26(1-2), 91-111. Doi:10.1300/J075v26n01_04

Harte, C., Barnes-Holmes, Y., Barnes-Holmes, D., \& McEnteggart, C. (2017). Persistent RuleFollowing in the Face of Reversed Reinforcement Contingencies: The Differential Impact of Direct Versus Derived Rules. Behavior Modification, 41(6), 743-763.

Doi:10.1177/0145445517715871

Hayes, S. C., Brownstein, A. J., Haas, J. R., \& Greenway, D. E. (1986). Instructions, multiple schedules, and extinction: Distinguishing rule-governed from schedule-controlled behavior. Journal of the Experimental Analysis of Behavior, 46(2), 137-147. 
581

582

583

584

585

586

587

588

589

590

591

592

593

594

595

596

597

598

599

600

601

602

603

604

605

606

607

608

609

610

611

612

613

614

615

616

617

618

619

620

\section{Doi:10.1901/jeab.1986.46-137}

Hayes, S. C., \& Gifford, E. V. (1997). The trouble with language: Experiential Avoidance, Rules, and the Nature of Verbal Events. Psychological Science, 8(3),170-173.

Doi:10.1111/j.1467-9280.1997.tb00405.x

Hayes, S. C., Villatte, M., Levin, M., \& Hildebrandt, M. (2011). The Annual Review of Clinical Psychology is online. Annu. Rev. Clin. Psychol, 7, 141-168. doi :10.1146/annurev-clinpsy032210-104449

Higgins J. P. T. \& Altman D. G. (Eds.) (2008). Chapter 8: Assessing risk of bias in included studies. In: Higgins J. P. T., \& Green S. (Eds.). Cochrane Handbook for Systematic Reviews of Interventions (Version 5.0, pp. 187-241). Chichester, UK: John Wiley \& Sons.

Hojo, R. (2002). Effects of instructional accuracy on a conditional discrimination task. The Psychological Record, 52(4), 493-506.

Hughes, S., \& Barnes-Holmes, D. (2015). Relational Frame Theory: The Basic Account. In R. Zettle, S. C. Hayes, D. Barnes-Holmes, \& T. Biglan (Eds), Wiley Handbook of contextual behavioural science (pp. 178-226). West Sussex, UK: Wiley-Blackwell.

Joober, R., Schmitz, N., Lawrence, A., \& Boksa, P. (2012). Publication bias: What are the challenges and can they be overcome? J Psychiatry Neurosc, 37(3), 149-152.

Joyce, J. H., \& Chase, P. N. (1990). Effects of response variability on the sensitivity of rulegoverned behavior. Journal of the Experimental Analysis of Behavior, 54, 251-262.

Kissi, A., Hughes, S., De Schryver, M., De Houwer, J., \& Crombez, G. (2018). Examining the Moderating Impact of Plys and Tracks on the Insensitivity Effect: a Preliminary Investigation. The Psychological Record, 68(4), 431-440. Doi:10.1007/s40732-018-0286-z

Kissi, A., Hughes, S., Mertens, G., Barnes-Holmes, D., De Houwer, J., \& Crombez, G. (2017). A Systematic Review of Pliance, Tracking, and Augmenting. Behavior Modification, 41(5), 683-707. Doi:10.1177/0145445517693811

Kollins, S. H., Lane, S. D., \& Shapiro, S. K. (1997). Experimental analysis of childhood psychopathology: A laboratory matching analysis of the behavior of children diagnosed with Attention-Deficit Hyperactivity Disorder (ADHD). Psychological Record, 47, 25-44.

Koricheva, J. \& Gurevitch, J. (2013). Place of Meta-analysis among Other Methods of Research Synthesis. In J. Koricheva, J. Gurevitch, \& K. Mengersen (Eds.). Handbook of MetaAnalysis in Ecology and Evolution. (pp. 3-13). Princeton, NJ: Princeton University Press.

Kroger-Costa, A.,\& Abreu-Rodrigues, J. (2012). Effects of historical and social variables on instruction following. The Psychological Record,62(4), 691-705.

Kudadjie-Gyamfi, E., \& Rachlin, H. (2002). Rule-governed versus contingency-governed behavior in a self-control task: Effects of changes in contingencies. Behavioural Processes, 57(1), 29-35. Doi:10.1016/S0376-6357(01)00205-4

Lefrancois, J. R., Chase, P. N., \& Joyce, J. H. (1988). The effects of a variety of instructions on human fixed-interval performance, Journal of the Experimental Analysis of Behavior, 49(3), 383-393.

McAuliffe, D., Hughes, S., \& Barnes-Holmes, D. (2014). The dark-side of rule governed 
621

622

623

624

625

626

627

628

629

630

631

632

633

634

635

636

637

638

639

640

641

642

643

644

645

646

647

648

649

650

651

652

653

654

655

656

657

658

659

660

behavior: An experimental analysis of problematic rule-following in an adolescent population with depressive symptomatology. Behavior Modification, 38, 587-613. Doi:10.1177/0145445514521630

McCracken, L. M. (2005). Contextual cognitive-behavioral therapy for chronic pain. Seattle, WA: International Association for the Study of Pain.

McCracken, L. M., Carson, J. W., Eccleston, C., \& Keefe, F. J. (2004). Acceptance and change in the context of chronic pain. Pain, 107, 159-166. Doi:10.1016/j.pain.2004.02.006

Miller, J. R., Hirst, J. M., Kaplan, B. A., DiGennaro Reed, F. D., \& Reed, D. D. (2014). Effects of Mands on Instructional Control: A Laboratory Simulation. The Analysis of Verbal Behavior, 30(2), 100-112. Doi:10.1007/s40616-014-0015-x

Moher, D., Liberati, A., Tetzlaff, J., \& Altman, D. G. (2009). Preferred reporting items for systematic reviews and meta-analyses: the PRISMA statement. The PRISMA Statement. PLoS Med 6(7): e1000097. Doi:10.1371/journal.pmed1000097

Monestès, J. L., Greville, W. J., \& Hooper, N. (2017). Derived insensitivity: Rule-based insensitivity to contingencies propagates through equivalence. Learning and Motivation, 59, 55-63. Doi:10.1016/J.LMOT.2017.08.003

Monestès, J. L., Villatte, M., Stewart, I., \& Loas, G. (2014). Rule-Based Insensitivity and Delusion Maintenance in Schizophrenia. The Psychological Record, 64(2), 329-338. Doi:10.1007/s40732-014-0029-8

Ninness, H. A., C. \& Ninness, S. K. (1998). Superstitious math performance: Interactions between rules and scheduled contingencies. The Psychological Record, 48(1), 45-62.

NTP (2015). Handbook for conducting a literature-based health assessment using OHAT approach for systemic review and evidence integration. Retrieved from https://ntp.niehs.nih.gov/ntp/ohat/pubs/handbookjan2015_508.pdf

Otto, T. L., Torgrud, L. J., \& Holborn, S. W. (1999). An operant blocking interpretation of instrcuted insensitivity to schedule contingencies. Psychological Record, 49, 663-684. Doi:10.1007/BF03395334

Rosenfarb, I. W., Newland, M. C., Brannon, S. E., Howey, D. S. (1992). Effects of selfgenerated rules on the development of schedule-controlled behavior. Journal of the Experimental Analysis of Behavior, 58(1), 107-121. Doi: 10.1901/jeab.1992.58-107

Schulz, K. F., Altman, D. G., \& Moher, D. (2010). CONSORT 2010 Statement: Updated guidelines for reporting parallel group randomised trials. BMC Medicine.

Doi:10.1186/1741-7015-8-18

Shimoff, E., Catania, A. C., \& Matthews, B. A. (1981). Uninstructed human responding: Sensitivity of low-rate performance to schedule contingencies. Journal of the Experimental Analysis of Behavior, 36(2), 207-220. Doi:10.1901/jeab.1981.36-207

Souza, A. S., Pontes, T. N. R., \& Abreu-Rodrigues, J. (2012). Varied but not necessarily random: Human performance under variability contingencies is affected by instructions. Learning and Behavior, 40(4), 367-379. Doi:10.3758/s13420-011-0058-y

Svartdal, F. (1989). Shaping of rule-governed behaviour. Scandinavian Journal of Psychology,

Peer) reviewing PDF | (2020:01:45226:1:1:NEW 28 May 2020) 
661

662

663

664

665

666

667

668

669

670

671

672

673

674
30(4), 304-314. Doi:10.1111/j.1467-9450.1989.tb01093.x

Svartdal, F. (1995). When feedback contingencies and rules compete: Testing a boundary condition for verbal control of instrumental performance. Learning and Motivation, 221238.

Thornton, A., \& Lee, P. (2002). Publication bias in meta-analysis: its causes and consequences. Journal of Clinical Epidemiology, 53(2), 207-216.

Torgrud, L. J., Holborn, S. W., \& Zak, R. D. (2006). Determinants of human fixed-interval performance following varied exposure to reinforcement schedules. Psychological Record, 56(1), 105-133. Doi:10.1007/BF03395540

Törneke, N., Luciano, C., \& Salas, S. V. (2008). Rule-governed behavior and psychological problems. International Journal of Psychology and Psychological Therapy, 8(2), 141-156. Van Ryckeghem, D. M. L., Van Damme, S., Eccleston, C., \& Crombez, G. (2018). The efficacy of attentional distraction and sensory monitoring in chronic pain patients: A meta-analysis. Clinical Psychology Review, 59, 16-29. 
Figure 1

Flow diagram of the study selection process. 
Records identified through database searching $(n=1459)$
Additional novel records identified through other sources

$$
(n=5)
$$

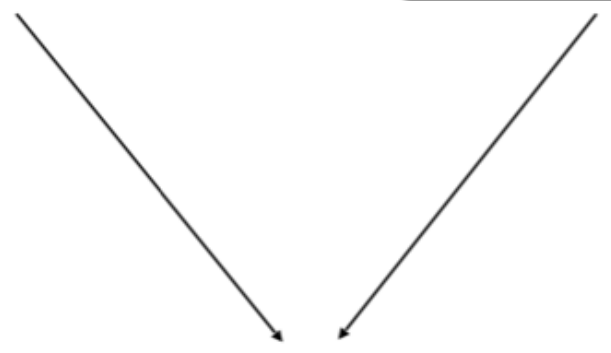

Records screened $(n=1464)$

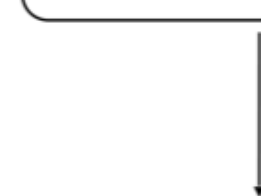

Eligible full-text journal articles

( $n=18$, consisting of 22 individual studies)

Records excluded $(n=1446)$

- Other topic $(n=1044)$

- Non-journal articles $(n=207)$

- Journal articles published in another language $(n=123)$

- Journal articles, but not enough information to assess eligibility $(n=3)$

- Non-experimental $(n=6)$

- Non-adult samples $(n=14)$

- Sample size $<10$ per group or single case study $(n=41)$

- No contingency change or manipulation of accurate rules $(n=8)$

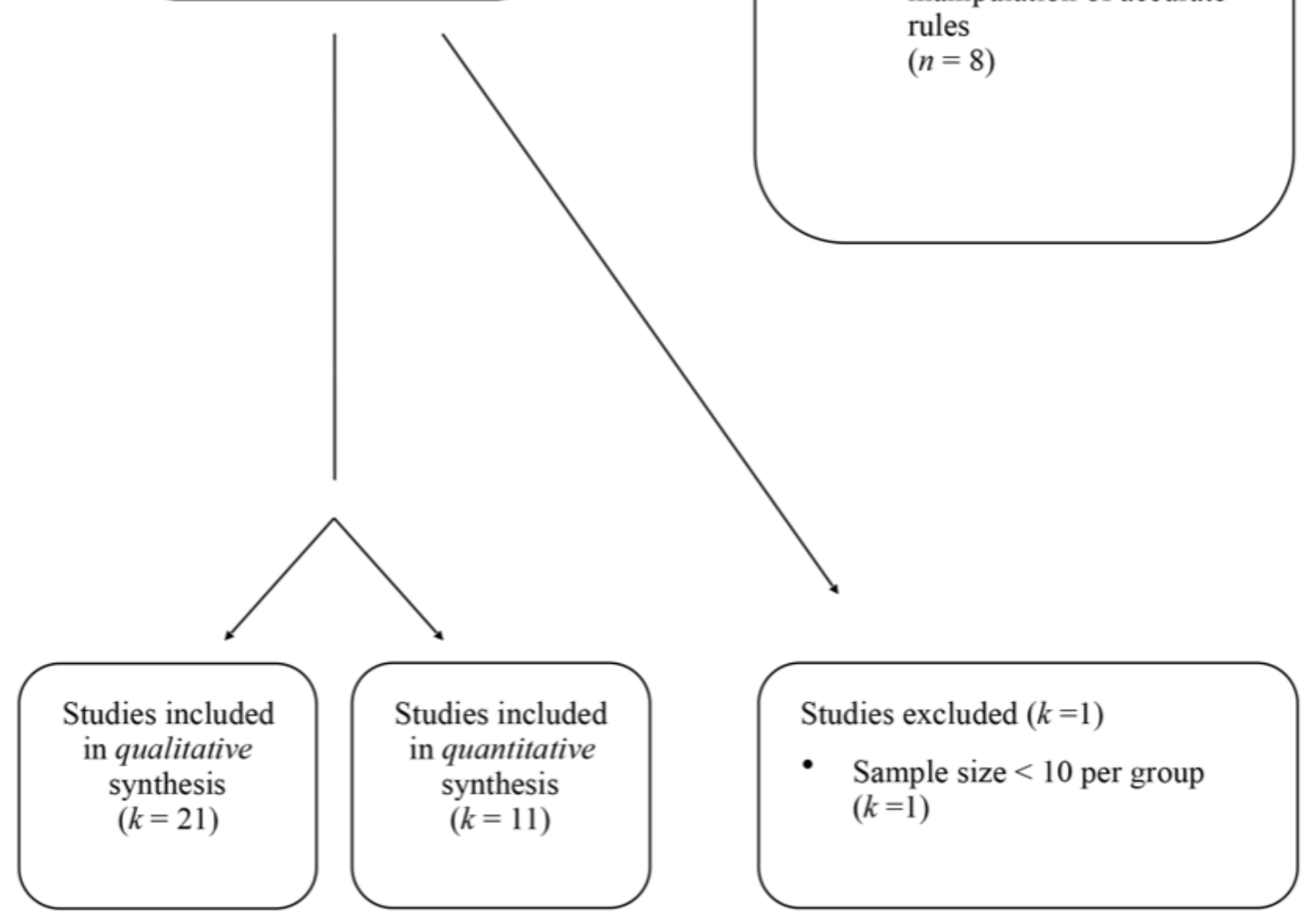


Table $\mathbf{1}$ (on next page)

Coded study characteristics. 


\section{Type of task}

Conditional discrimination task

Baruch et al.

\section{Cerutti}

(1991)

Cerutti

(1994)

Dixon et al.

(2000)

Haas and Hayes

(2006)
Conditional discrimination task

Gambling task

Participants were allocated to one of the experimental groups

Participants were allocated to one of the experimental groups
Experimental design

Procedure

Non-instructed task

contingencies reversal

Instructed task contingencies reversal

Participants were allocated to one of the experimental groups

Instructed task contingencies reversal

Non-instructed task contingencies change

Non-instructed task

contingencies change
Analytic method

Conclusions about RBIE are drawn by comparing performances between groups after a contingency change

Conclusions about RBIE are drawn by comparing performances between groups after a contingency change

Conclusions about RBIE are drawn by comparing performances between groups after a contingency change

Conclusions about RBIE are drawn by comparing performances between groups after a contingency change

Conclusions about RBIE are drawn by comparing performances between groups after a contingency change 
Harte et al.

Conditional discrimination task

(2017 -

Experiment 1)

Harte et al.

Conditional discrimination task

(2017 -

Experiment 2)

Hayes et al.

(1986)

Kissi et al.

(2018)

Kudadjie-Gyamfi

and Rachlin

LeFrancois et al.

(1988)
Conditional discrimination task

Participants were allocated to one of the experimental groups

Conditional discrimination task

Distributed choice paradigm where reinforcement could be increased if participants minimized the delay between a choice and its outcome

Task in which reinforcement was dependent upon button presses

Participants were allocated to one of the experimental groups

Participants were allocated to one of the experimental groups

Participants were allocated to one of the experimental groups
Participants were allocated to one of the experimental groups

Non-instructed task contingencies change

Participants were allocated to one of the experimental groups

Non-instructed task contingencies reversal

Non-instructed task contingencies reversal

Non-instructed task contingencies reversal

Non-instructed task contingencies change
Non-instructed task contingencies change
Conclusions about RBIE are drawn by comparing performances between groups after a contingency change

Conclusions about RBIE are drawn by comparing performances between groups after a contingency change

Conclusions about RBIE are drawn by comparing performances between groups after a contingency change

Conclusions about RBIE are drawn by comparing performances between groups after a contingency change

Conclusions about RBIE are drawn by comparing performances between groups after a contingency change

Conclusions about RBIE are drawn by comparing performances between groups after a contingency change 
Monestès et al. Conditional discrimination task (2017)

Monestès et al.

Otto et al.

(1999-

Experiment 1)

Otto et al.

(1999 -

Experiment 2)

Shimoff et al.

Souza et al.

Svartdal

(1989)

Conditional discrimination task

Conditional discrimination task

Conditional discrimination task to generate three-digit sequences that met a variability reinforcement

Task in which participants had to count clicks and insert the contingencies change criterion in order to receive number of clicks that they thought they heard in order to receive reinforcement
Participants were allocated to one of the experimental groups

Participants were allocated to one of the experimental groups

Participants were allocated to one of the experimental groups

Non-instructed task contingencies change

Participants were allocated to one of the experimental groups

Non-instructed task contingencies change

Participants were allocated to one of the experimental groups

Non-instructed task

Non-instructed task contingencies reversal

Non-instructed task contingencies reversal

Instructed task contingencies change

Participants were allocated to one of the experimental groups

Non-instructed task contingencies change
Conclusions about RBIE are drawn by comparing performances between groups after a contingency change

Conclusions about RBIE are drawn by comparing performances between groups after a contingency change

Conclusions about RBIE are drawn by comparing performances between groups after a contingency change

Conclusions about RBIE are drawn by comparing performances between groups after a contingency change

Conclusions about RBIE are drawn by comparing performances between groups after a contingency change

Conclusions about RBIE are drawn by comparing performances between groups after a contingency change
Conclusions about RBIE are drawn by comparing performances between groups after a contingency change 
Svartdal

(1995 -

Experiment 2)

Torgrud et al.

(2006 -

Experiment 1)

Torgrud et al.

(2006 -

Experiment 2)
Task in which reinforcement was dependent upon participants' pattern of key

Conditional discrimination task presses

Task in which reinforcement was dependent upon participants' pattern of key presses

Non-instructed and instructed

Participants were allocated to one of the experimental groups

Participants were allocated to one of the experimental groups

Participants were allocated to one of the experimental groups
Non-instructed task contingencies change

contingency change

Non-instructed task

contingencies change
Conclusions about RBIE are drawn by comparing performances between groups after a contingency change

Conclusions about RBIE are drawn by comparing performances between groups after a contingency change

Conclusions about RBIE are drawn by comparing performances between groups after a contingency change 
Table 2 (on next page)

Coded study characteristics. 
1

\begin{tabular}{|c|c|c|c|c|c|}
\hline & $\begin{array}{l}\text { Report of exact } \\
\text { rules/instructions used }\end{array}$ & Rule-delivery & Rule-generation & $\begin{array}{l}\text { Reinforcement } \\
\text { schedule(s) }\end{array}$ & $\begin{array}{l}\text { Behavioral } \\
\text { responses }\end{array}$ \\
\hline $\begin{array}{l}\text { Baruch et al. } \\
\text { (2007) }\end{array}$ & Yes & Written & Socially-generated & Continuous & $\begin{array}{l}\text { Discrete choice } \\
\text { responses }\end{array}$ \\
\hline $\begin{array}{l}\text { Cerutti } \\
(1991)\end{array}$ & Yes & Written & Self-generated & Intermittent & $\begin{array}{l}\text { Discrete simple and } \\
\text { discrete choice } \\
\text { responses }\end{array}$ \\
\hline $\begin{array}{l}\text { Cerutti } \\
(1994)\end{array}$ & Yes & Written & Self-generated & Intermittent & $\begin{array}{l}\text { Discrete simple and } \\
\text { discrete choice } \\
\text { responses }\end{array}$ \\
\hline $\begin{array}{l}\text { Dixon et al. } \\
(2000)\end{array}$ & Yes & Written & Socially-generated & Intermittent & $\begin{array}{l}\text { Discrete simple } \\
\text { responses }\end{array}$ \\
\hline $\begin{array}{l}\text { Haas and Hayes } \\
(2006)\end{array}$ & Yes & Written and orally & $\begin{array}{l}\text { Socially -and self- } \\
\text { generated }\end{array}$ & $\begin{array}{l}\text { Continuous and } \\
\text { intermittent }\end{array}$ & $\begin{array}{l}\text { Discrete simple } \\
\text { responses }\end{array}$ \\
\hline $\begin{array}{l}\text { Harte et al. } \\
(2017-\end{array}$ & Yes & Unclear & $\begin{array}{l}\text { Socially -and self- } \\
\text { generated }\end{array}$ & Continuous & $\begin{array}{l}\text { Discrete choice } \\
\text { responses }\end{array}$ \\
\hline
\end{tabular}




\begin{tabular}{|c|c|c|c|c|c|}
\hline $\begin{array}{l}\text { Harte et al. } \\
(2017- \\
\text { Experiment 2) }\end{array}$ & Yes & Unclear & $\begin{array}{l}\text { Socially -and self- } \\
\text { generated }\end{array}$ & Continuous & $\begin{array}{l}\text { Discrete choice } \\
\text { responses }\end{array}$ \\
\hline $\begin{array}{l}\text { Hayes et al. } \\
\text { (1986) }\end{array}$ & Yes & Written and orally & Socially-generated & Intermittent & $\begin{array}{l}\text { Discrete simple } \\
\text { responses }\end{array}$ \\
\hline $\begin{array}{l}\text { Kissi et al. } \\
(2018)\end{array}$ & Yes & Written & Socially-generated & Continuous & $\begin{array}{l}\text { Discrete choice } \\
\text { responses }\end{array}$ \\
\hline $\begin{array}{l}\text { Kudadjie-Gyamfi and } \\
\text { Rachlin } \\
(2002)\end{array}$ & Yes & Written & $\begin{array}{l}\text { Socially -and self- } \\
\text { generated }\end{array}$ & $\begin{array}{l}\text { Continuous and } \\
\text { conditional }\end{array}$ & $\begin{array}{l}\text { Discrete choice } \\
\text { responses }\end{array}$ \\
\hline $\begin{array}{l}\text { LeFrancois et al. } \\
(1988)\end{array}$ & Yes & Written & Socially-generated & Intermittent & $\begin{array}{l}\text { Discrete simple } \\
\text { responses }\end{array}$ \\
\hline $\begin{array}{l}\text { Monestès et al. } \\
(2017)\end{array}$ & Yes & Written and orally & Socially-generated & Intermittent & $\begin{array}{l}\text { Discrete choice } \\
\text { responses }\end{array}$ \\
\hline $\begin{array}{l}\text { Monestès et al. } \\
\text { (2014) }\end{array}$ & Yes & Orally & $\begin{array}{l}\text { Socially -and self- } \\
\text { generated }\end{array}$ & Intermittent & $\begin{array}{l}\text { Discrete simple } \\
\text { responses }\end{array}$ \\
\hline $\begin{array}{l}\text { Otto et al. } \\
(1999-\end{array}$ & Yes & Written and orally & Socially-generated & Intermittent & $\begin{array}{l}\text { Discrete simple } \\
\text { responses }\end{array}$ \\
\hline
\end{tabular}

Experiment 1) 


\begin{tabular}{|c|c|c|c|c|c|}
\hline $\begin{array}{l}\text { Otto et al. } \\
(1999- \\
\text { Experiment 2) }\end{array}$ & Yes & Written and orally & Socially-generated & Intermittent & $\begin{array}{l}\text { Discrete simple } \\
\text { responses }\end{array}$ \\
\hline $\begin{array}{l}\text { Shimoff et al. } \\
\text { (1981) }\end{array}$ & Yes & Written & Socially-generated & Intermittent & $\begin{array}{l}\text { Discrete simple } \\
\text { responses }\end{array}$ \\
\hline $\begin{array}{l}\text { Souza et al. } \\
(2012)\end{array}$ & Yes & Written & Socially-generated & Continuous & $\begin{array}{l}\text { Complex response } \\
\text { (i.e., three-digit } \\
\text { combinations) }\end{array}$ \\
\hline $\begin{array}{l}\text { Svartdal } \\
\text { (1989) }\end{array}$ & Yes & Unclear & Socially-generated & $\begin{array}{l}\text { Continuous and } \\
\text { intermittent }\end{array}$ & $\begin{array}{l}\text { Discrete simple } \\
\text { responses }\end{array}$ \\
\hline $\begin{array}{l}\text { Svartdal } \\
(1995- \\
\text { Experiment 2) }\end{array}$ & Yes & Unclear & Socially-generated & Intermittent & $\begin{array}{l}\text { Discrete simple } \\
\text { responses }\end{array}$ \\
\hline $\begin{array}{l}\text { Torgrud et al. } \\
(2006- \\
\text { Experiment } 1)\end{array}$ & Yes & Both & Socially-generated & Intermittent & $\begin{array}{l}\text { Discrete simple } \\
\text { responses }\end{array}$ \\
\hline $\begin{array}{l}\text { Torgrud et al. } \\
(2006- \\
\text { Experiment 2) }\end{array}$ & Yes & Both & Socially-generated & Intermittent & $\begin{array}{l}\text { Discrete simple } \\
\text { responses }\end{array}$ \\
\hline
\end{tabular}


Table 3 (on next page)

Coded task characteristics. 
1

\begin{tabular}{|c|c|c|c|c|}
\hline & Consequential stimuli & $\begin{array}{l}\text { Announcement of } \\
\text { contingency change(s) }\end{array}$ & $\begin{array}{l}\text { Description of } \\
\text { experimenter }\end{array}$ & Presence of experimenter \\
\hline $\begin{array}{l}\text { Baruch et al. } \\
(2007)\end{array}$ & $\begin{array}{l}\text { Points that were exchangeable for } \\
\text { a monetary reward }\end{array}$ & Unclear & Yes & No \\
\hline $\begin{array}{l}\text { Cerutti } \\
(1991)\end{array}$ & $\begin{array}{l}\text { Points that were exchangeable for } \\
\text { a monetary reward and a tone }\end{array}$ & Unclear & No & Yes \\
\hline $\begin{array}{l}\text { Cerutti } \\
(1994)\end{array}$ & Points & Unclear & No & Unclear \\
\hline $\begin{array}{l}\text { Dixon et al. } \\
(2000)\end{array}$ & $\begin{array}{l}\text { Chips that were exchangeable for } \\
\text { extra credit points }\end{array}$ & Unannounced & No & No \\
\hline $\begin{array}{l}\text { Haas and Hayes } \\
(2006)\end{array}$ & $\begin{array}{l}\text { Points that were exchangeable for } \\
\text { a monetary reward }\end{array}$ & Unannounced & No & Unclear \\
\hline $\begin{array}{l}\text { Harte et al. } \\
(2017 \text { - Experiment } 1)\end{array}$ & Points & Unannounced & No & Unclear \\
\hline $\begin{array}{l}\text { Harte et al. } \\
(2017 \text { - Experiment 2) }\end{array}$ & Points & Unannounced & No & Unclear \\
\hline $\begin{array}{l}\text { Hayes et al. } \\
\text { (1986) }\end{array}$ & $\begin{array}{l}\text { Points that were exchangeable for } \\
\text { a monetary reward }\end{array}$ & Unclear & No & No \\
\hline Kissi et al. & Points & Unannounced & No & No \\
\hline
\end{tabular}


(2018)

Kudadjie-Gyamfi and

Rachlin

(2002)

LeFrancois et al.

(1988)

Monestès et al.

(2017)

Monestès et al.

(2014)

Otto et al.

(1999 - Experiment 1)

Otto et al.

(1999 - Experiment 2)

Shimoff et al.

(1981)
Points that were exchangeable for Unclear a monetary reward and time

delays

Points that were exchangeable for Unclear a monetary reward

Points

Unclear

Unannounced

Unclear

Unclear

Points

Points that were exchangeable for Unclear a monetary reward
No

Unclear

No

Unclear

No

Unclear

Yes

Unclear

Unclear

Unclear 
Souza et al.

(2012)

Svartdal

(1989)

Svartdal

(1995 - Experiment 2)

Torgrud et al.

(2006 - Experiment 1)

Torgrud et al.

(2006 - Experiment 2)
Points that were exchangeable for Unannounced a monetary reward

Unclear

Sounds and lights

Points that were exchangeable for Unclear a monetary reward

Points that were exchangeable for Unclear a monetary reward

Announced

Announced
No

Unclear

No

No

No

Unclear

No

Unclear 
Table 4 (on next page)

Overview of vote-counting results. 
Studies used to answer Research Question 1 ("Is there evidence for the rule-based insensitivity effect in adults")

Type of change

Experiment

Evidence for the RBIE

Task-contingencies

Dixon et al. (2000)

Haas \& Hayes (2006)

Harte et al. (2017 - Experiment 1)

Harte et al. (2017 - Experiment 2)

Hayes et al. (1986)

Kissi et al. (2018)

Kudadjie-Gyamfi and Rachlin (2002)

LeFrancois et al. (1988)

Monestès et al. (2017)

Monestès et al. (2014)

Otto et al. (1999 - Experiment 2)

Shimoff et al. (1981 - Experiment 1)

Souza et al. (2012)

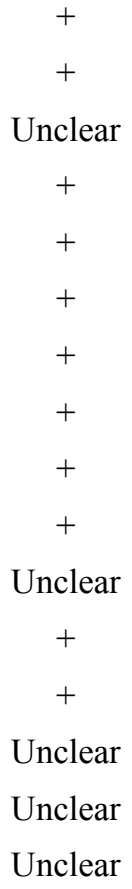

Instructions

Svartdal (1989)

Unclear

Torgrud et al. (2006 - Experiment 1)

Unclear

Torgrud et al. (2006 - Experiment 2)

Unclear

Cerutti (1991)

Unclear

Cerutti (1994)

Unclear

Task-contingencies and instructions

Otto et al. (1999 - Experiment 1)

Unclear

Studies used to answer Research Question 2 ("Do adults suffering from psychological problems display a larger RBIE compared to their non-clinical counterparts?").

Type of change

Experiment
Evidence for a larger RBIE in the clinical group

Task-contingencies

Baruch et al. (2007)

Unclear

2 Note. '+' indicates that there was evidence for the RBIE. '-' indicates that participants in the

3 rule-group(s) adapted to the change in the task-contingencies or instructions. 'Unclear' indicates

4 that there was insufficient information to cast votes. 